DOI: $10.20472 /$ IAC.2019.048.023

\title{
THANATCHON JANGKHUM
}

Rajamangala University of Technology Suvarnabhumi, Thailand

\section{BEHAVIOR TOURISM OF TOURIST WHO COME TO 100 - YEAR - OLD SAMCHUK MARKET FOR TOURIST PURPOSE SUPHANBURI PROVINCE, THAILAND}

\begin{abstract}
:
The purposes of this research has 2 objectives, Which are studying of Behavior Tourism and the factors that have impact on Tourist Who come to 100 - Year - Old Samchuk Market for Tourist Purpose. The research uses questionnaire to collect data from 400 Tourist. The data analysis methods which have been used in this research are percentage calculation, mean, standard deviation and the testing of relationship of variation factors by using Chi-square

The results Behavior of Tourist to find that The percentage of female is $53 \%$ and male is $47 \%$ Tourist age between 50 - 59 years old is $33.3 \%$ of tourist who have bachelor degree is $46.5 \%$, unmarried is $50.8 \%$, government official is $34.3 \%$, travel with staff is 47.3 , travel for tourist purpose seminar is $55.8 \%$, impression in uniqueness of tourist site is $49.5 \%$, money spending for tourist per time per person amount $1000-2000$ baht is $5.3 \%$. The most popular goods is food and beverage is $60.8 \%$. The percentage of most of the tourists who travel during weekend is $70.8 \%$, of tourists who travel between January to March is $47.8 \%$, of tourists who get information from friend is $42.8 \%$, of tourists who want to re-visit 100 - Year - Old Samchuk Market is 53.5. The factors related to goods character, tourist designation places and tourist promotion package from the government have much influent on decision making of tourist to visit 100 - Year - Old Samchuk Market and the analysis of factors that have correlation with tourist behavior on money spending per time per person of tourist who visit 100 - Year - Old Samchuk Market The Gender, age, education level, married status, career, monthly income, goods character, tourist designation places and tourist promotion package from the government have related to with tourist behavior in term of money spending per time per person at the statistical significant at 0.05 level.
\end{abstract}

\section{Keywords:}

Behavior Tourism, Samchuk Market, Spending Tourism

JEL Classification: A10, D03, D11 


\section{Introduction}

Thailand's tourism industry plays a significant role in the economic development of the country, generating millions of millions of baht in revenue annually for Thailand. The industry creates employment for people which leads to income distribution and the growth of various tourismrelated businesses and services. Even though Thailand has a wide variety of tourism, the tourism activity is mainly only concentrated in some major cities of the country, causing income concentration and the development that is restricted merely to Thailand's large cities; not the secondary cities, or less visited areas which have little tourist traffic. Therefore there has been a high discrepancy in income distribution between local communities in secondary cities and those in major cities. As a result, the Tourism Authority of Thailand has made changes to achieve the equality of income distribution and to reduce the inequality of development. Comprehensive development has been promoted. The 2019 Tourism Promotion plan of the Tourism Authority of Thailand is aimed to create tourism hotspots (Preferred Destinations) sustainably by increasing tourism revenue continuously, in a balanced manner and inclusively by presenting the value of travelling in Thailand, enabling tourists to have value for experience and broadening aspects of unique local Thai experience. With innovative database operation, taking the needs of travellers and other stakeholders into consideration, being responsible for the society and environment and strengthening local communities from within are supported. Under the Unique Local Thai Experience initiative, promotion of tourism markets in the country is achieved by changing the perspectives of people. In-depth travelling in Thailand and participation of local people and people who preserve lifestyle, culture and local wisdom (the Tourism Council of Thailand, 2019).

Suphanburi province is one of interesting secondary provinces in the central region of Thailand due to the convenience and ease of transportation. Tourists can visit many destinations within one day, making it a good value for money. An extensive range of tourist destinations allows tourists to plan their own itineraries, especially in a unique authentic Thai way-of-life attraction such as 100 - Year - Old Samchuk Market that still maintains its social and cultural identity of local lifestyles as well as shops, markets and old architecture. Moreover, it is a place with various kinds of merchandise and delicious foods to shop for. Therefore, recognizing tourists' travelling behavior and tourists' spending patterns visiting the market can result in useful information on how to conceive and develop a plan to stimulate tourism and attract more tourists to the market. So, Suphanburi can serve as one of the secondary provinces that can generate increasing revenue in tourism for the nation.

\section{Research Objectives}

1. To study the travelling behavior of tourists who went to 100 - Year - Old Samchuk Market, Samchuk district, Suphanburi province.

2. To study factors related to the spending patterns of tourists who went to 100 - Year - Old Samchuk Market, Samchuk district, Suphanburi province 


\section{Literature Review}

\section{Economics of travel and tourism}

Remarked that travelling can occur only when the demand and supply of travel meet or when tourists journey to their expected destinations. A combination of factors is required for travelling networks to take place such as travelling logistics and marketing and data management agents. In order to create the demand and supply of travel, the demand of travel, which is a tourist's desire to make a trip to purchase products or services at a given tourist destination must exist and the demand of their travel must be accompanied by their needs, buying powers and willingness to pay for those products or services at a given time. On the other hand, the supply of travel is a collection of various products or services that have the attraction to be presented to a tourist. The gathering of products or services is actions characterized by the connection between upstream and downstream activities. Travelling merchandise includes products or services, atmospheres or experiences gained by a tourist who goes to a given destination, with the products or services being different from other general goods. (Mingsan Khaosaard and team, 2013).

\section{Economics on consumption behavior}

Narathip Chutiwong (2007: 87) defined "consumer behavior" as any circumstances faced by a consumer with a limited amount of money, a market price of a product and the desire to seek highest satisfaction.The consumer has criteria in alloting their money for products or services, and Kamolphop Thippala (2012) wrote that "consumer behavior" is processes that express individual reactions consisting of processes of data searching, purchasing, evaluation and handling that bought product or service to satisfy their needs. And consumers around the world have different demographic features; for example, sex, age, income, education level, marital status, religion, profession etc., which makes consumer behavior or viewpoints of individual customers about a product or service different, resulting in differences in choice of products or services. A consumer behavior in deciding to buy a product or service is called "buying decision process."

\section{Research Methodology}

The study of the travelling behavior of tourists who visited 100 - Year - Old Samchuk Market is survey research employing a quantitative tool such as questionnaires by collecting data from 400 tourists who visited 100 - Year - Old Samchuk Market by means of convenience sampling, frequency distribution and percentage to analyze data of personal factors and the travelling behavior of tourists who visited the market. Arithmetic mean and standard deviation (S.D.) were also utilized to examine the characteristics of products, tourist attractions, tourism promotion by the state and analyze elements associated with the expenses of tourists who visited the market using Chi-square test at 95 confidence intervals for the hypothesis test. 


\section{Results}

The researchers collected the data from 400 tourists who visited the market and the analysis resultsare as follows: the tourists were chiefly female at 53 percent, the tourists at the age range of 50-59 years stood at 33.3 percent, the tourists with a bachelor's degree were at 46.5 percent, those with a single marital status amounted to 50.8 percent, and the tourists who were civil servants stood at 34.3 percent according to Table 1 as follows.

Table 1: analysis of personal data by gender, age, education level, marital status and profession.

\begin{tabular}{|c|c|c|}
\hline Personal factors & Number of people & Percent \\
\hline \multicolumn{3}{|l|}{ 1. Gender } \\
\hline Male & 188 & 47 \\
\hline Female & 212 & 53 \\
\hline Total & 400 & 100 \\
\hline \multicolumn{3}{|l|}{ 2. Age } \\
\hline Below 20 years of age & 96 & 24 \\
\hline $20-29$ years & 69 & 17.3 \\
\hline $30-39$ years & 59 & 14.8 \\
\hline $40-49$ years & 15 & 3.8 \\
\hline $50-59$ years & 133 & 33.1 \\
\hline 60 and above & 28 & 7 \\
\hline Total & 400 & 100 \\
\hline \multicolumn{3}{|l|}{ 3. Education level } \\
\hline Secondary school & 114 & 28.5 \\
\hline Diploma & 100 & 25 \\
\hline Bachelor's degree & 186 & 46.5 \\
\hline Total & 400 & 100 \\
\hline \multicolumn{3}{|l|}{ 4. Marital Status } \\
\hline Single & 203 & 50.8 \\
\hline Marriage & 178 & 44.5 \\
\hline Divorced & 19 & 4.7 \\
\hline Total & 400 & 100 \\
\hline \multicolumn{3}{|l|}{ 5. Profession } \\
\hline Students & 96 & 24 \\
\hline Housewife & 43 & 10.8 \\
\hline Civil servants & 137 & 34.2 \\
\hline Office workers & 90 & 22.5 \\
\hline Self-employed & 34 & 8.5 \\
\hline Total & 400 & 100 \\
\hline
\end{tabular}


Table 2: Analysis of the travelling behaviour of tourists who visited the $100-$ Year - Old Samchuk Market.

\begin{tabular}{|c|c|c|}
\hline Travelling behavior of tourists & Number of people & Percent \\
\hline \multicolumn{3}{|l|}{ 1. Co-traveller types } \\
\hline Alone & 122 & 30.5 \\
\hline Family / Relatives & 76 & 19 \\
\hline Friends & 13 & 3.3 \\
\hline Party of colleagues & 189 & 47.2 \\
\hline Total & 400 & 100 \\
\hline \multicolumn{3}{|l|}{ 2. Travelling propose } \\
\hline Relaxing & 41 & 10.2 \\
\hline Eating & 82 & 20.5 \\
\hline Shopping & 54 & 13.5 \\
\hline Meeting/seminar/work observation & 223 & 55.8 \\
\hline Total & 400 & 100 \\
\hline \multicolumn{3}{|l|}{ 3. Impression of visiting the market } \\
\hline Various travelling activities & 44 & 11 \\
\hline Culture, custom and local identity & 198 & 49.5 \\
\hline Clean and beautiful tourist attractions & 158 & 39.5 \\
\hline Total & 400 & 100 \\
\hline \multicolumn{3}{|l|}{ 4. Travelling expenses per person } \\
\hline Less than 1000 baht & 180 & 45 \\
\hline $1000-2000$ baht & 201 & 50.2 \\
\hline $2000-3000$ baht & 13 & 3.3 \\
\hline 3000 baht up & 6 & 1.5 \\
\hline Total & 400 & 100 \\
\hline \multicolumn{3}{|l|}{ 5. The space bought products } \\
\hline Food / Beverage & 243 & 60.8 \\
\hline Souvenirs/mementos & 114 & 28.5 \\
\hline Clothing & 37 & 9.2 \\
\hline Images of the Buddha & 6 & 1.5 \\
\hline Total & 400 & 100 \\
\hline \multicolumn{3}{|l|}{ 6. Travelling periods } \\
\hline Official holidays & 86 & 21.5 \\
\hline Weekends & 283 & 70.7 \\
\hline Annual leaves & 31 & 7.8 \\
\hline Total & 400 & 100 \\
\hline \multicolumn{3}{|l|}{ 7. Travelling periods } \\
\hline January - March & 191 & 47.8 \\
\hline April - June & 134 & 33.5 \\
\hline July - September & 65 & 16.2 \\
\hline \multirow{2}{*}{$\begin{array}{r}\text { October - December } \\
\text { Total }\end{array}$} & 10 & 2.5 \\
\hline & 400 & 100 \\
\hline Travelling behavior of tourists & Number of people & Percent \\
\hline \multicolumn{3}{|l|}{ 8. Sources of travelling information } \\
\hline Friends & 171 & 42.8 \\
\hline Internet & 33 & 8.3 \\
\hline Magazines/printed materials & 113 & 28.2 \\
\hline Advertisements by Suphanburi & 81 & 20.2 \\
\hline
\end{tabular}




\begin{tabular}{l|c|c}
\hline $\begin{array}{l}\text { Authority of Tourism } \\
\text { Others }\end{array}$ & 2 & 0.5 \\
\hline \multicolumn{1}{|c|}{ Total } & 400 & 100 \\
\hline 9. Desire to return & & \\
Wanting to return & 214 & 53.5 \\
\hline Not wanting to return & 186 & 46.5 \\
\hline Total & 400 & 100 \\
\hline
\end{tabular}

From table 2 displays the results of the analysis of the travelling behavior of tourists who visited 100 - Year - Old Samchuk Market. It reveals that most of the tourists were parties of colleagues at 47.3 percent, the tourists with the purposes of meetings, seminars and work observation were at 55.8 percent, those impressed by the culture, custom and local identity stood at 49.5 percent, travelling expenses per person at the range of 1,000-2,000 baht amounted to 50.3 percent, food and beverages were the-most-bought-products at 60.8 percent, travelling during the weekends was at 70.8 percent, the period of January-March was at 47.8 percent, getting travelling information from friends stood at 42.8 percent, wanting to return was at 53.5 percent

The revenue analysis of a sampling group of 400 tourists finds that most of the tourists earned 20,000 baht a month numbering 121 people at 30.3 percent, the second highest of revenue range was 15,000-20,000 baht a month amounting 116 people at 29 percent, a revenue range of 10,000-15,000 baht a month totaling 96 people were at 24 percent, a revenue range of 5,00010,000 baht a month numbering 61 people were at 15.2 percent, revenue less than 5,000 baht a month amounting to 6 people were at 1.5 percent respectively. The results of factors analysis such as product characteristics, tourist destinations and tourism promotion by the state were according to Table three as follows:

Table 3: The results of economic factor analysis

\begin{tabular}{|c|c|c|c|}
\hline \multirow{2}{*}{ Product characteristics } & \multicolumn{3}{|c|}{ Significant level } \\
\hline & $\bar{X}$ & S.D. & pretation \\
\hline 1. Variousness & 4.53 & 0.640 & greatest \\
\hline 2. Reasonable prices & 4.47 & 0.587 & many \\
\hline 3. Local identity & 4.53 & 0.718 & greatest \\
\hline $\begin{array}{l}\text { 4. Product quality corresponding with } \\
\text { prices }\end{array}$ & 4.30 & 0.620 & many \\
\hline Total & 4.46 & 0.641 & Man \\
\hline
\end{tabular}

\begin{tabular}{l|c|c|c}
\hline \multirow{2}{*}{\multicolumn{1}{c}{ Tourist destinations }} & \multicolumn{3}{c}{ Significant level } \\
\cline { 2 - 4 } & $\bar{X}$ & S.D. & \multicolumn{1}{c}{ Interpretation } \\
\hline 1. Uniqueness & 4.20 & 0.562 & many \\
2. Beautifulness & 4.05 & 0.218 & many \\
3. Cleanliness & 4.62 & 0.507 & greatest \\
4. Safety & 4.23 & 0.453 & many \\
\hline
\end{tabular}




\begin{tabular}{l|c|c|c}
\multicolumn{1}{c|}{ Total } & 4.27 & 0.435 & many \\
\hline \multicolumn{1}{c}{$\begin{array}{c}\text { Tourism promotion by } \\
\text { government support }\end{array}$} & $\overline{3}$ & \multicolumn{3}{c}{ Significant level } \\
\cline { 2 - 4 } & 3.60 & 0.794 & Interpretation \\
\hline 1. Increase in tourism diversity & 4.68 & 0.727 & moderate \\
\hline 2. Online publication & 3.90 & 0.441 & mantest \\
3. Booth advertisements & 3.31 & 0.561 & moderate \\
$\begin{array}{l}\text { 4. Designation of continuous official } \\
\text { holidays }\end{array}$ & & & many \\
\hline \multicolumn{1}{c}{ Total } & 3.87 & 0.630 & \\
\hline
\end{tabular}

According to table 3 , it reveals that the most two influential factors affecting the travelling expenses per person in terms of product characteristics by considering income were variousness of products and local identity of products with an arithmetic mean of 4.53 and standard deviation values of 0.640 and 0.718 . Regarding tourist destinations, cleanliness of tourist destinations had the most influence with an arithmetic mean of 4.62 and a standard deviation value of 0.507 . Concerning tourism promotion by the state, online publicity of tourism was at the highest level with an arithmetic mean of 4.68 and a standard deviation value of 0.727

Table 4: The analysis results of factors related to the travelling expenses of tourists who visited 100 - Year - Old Samchuk Market

\begin{tabular}{ccc}
\hline The relationship of variables & Sig & $\chi^{2}$ \\
\hline Gender & 0.000 & 54.981 \\
\hline Age & 0.000 & 168.101 \\
\hline Education level & 0.000 & 114.422 \\
\hline Marital status & 0.000 & 171.658 \\
\hline Profession & 0.000 & 239.387 \\
\hline Income per month & 0.000 & 193.363 \\
\hline Product characteristics & 0.000 & 196.232 \\
\hline Tourist destinations & 0.000 & 111.087 \\
\hline Tourism promotion by the State & 0.000 & 141.778 \\
\hline
\end{tabular}

Based on table 4, the factor test of the travelling expenses of tourists who visited $100-$ Year Old Samchuk Market using Chi-square statistics. It shows that gender, age, education level, marital status, profession, income per month, tourist destinations as well as tourism promotion by the state were all in relation to the travelling expenses of tourists who visited Sam Chook 100 Year Market at a statistical significance of 0.05 .

\section{Conclusion}

The study of travelling behavior of tourists who visited 100 - Year - Old Samchuk Market found that most tourists were female at 53\%, tourists aged 50-59 years of age stood at 33.3 percent, those with a bachelor's degree amounted to 46.5 percent, those who has a single marital status 
stood at 50.8 percent, civil servants stood at 34.3 percent, those travelling with parties at the workplace came at 47.3 percent, tourists with the purposes of meetings, seminars and work observation were at 55.8 percent, those impressed by the culture, custom and local identity of the market stood at 49.5 percent. The travelling expenses per person at a price range of 1,000-2,000 baht stood at 50.3 percent. Food and beverages were the most bought items at 60.8 percent. Those travelling at weekends came at 70.8 percent and travelling between January and March at 47.8 percent. Tourists who received travelling information from friends stood at 42.8 percent. Those who wanted to return to the market were at 53.5 percent. The economic factors most affecting the travelling expenses per person with regards to product characteristics when considering income were variousness of products and local identity of products having an arithmetic mean of 4.53 and standard deviation values of 0.640 and 0.718 . In terms of tourist destinations, cleanliness of tourist destinations came on top with an arithmetic mean of 4.62 and a standard deviation value of 0.507 . As for tourism promotion by the state, online publicity of tourism played the most important role with an arithmetic mean of 4.68 and a standard deviation value of 0.727 . In addition, sex, age, education level, marital status, profession, income per month, tourist destinations and tourism promotion by the state were associated with the travelling expenses of tourists who visited 100 - Year - Old Samchuk Market at a statistical significance of 0.05 .

\section{Discussion}

In the study, the researchers investigated the travelling behavior of tourists who visited $100-$ Year - Old Samchuk Market which can be elaborated as follows:

1. The travelling behavior of tourists visiting the market includes travelling as parties of colleagues (47.3 percent), travelling for the purposes of meetings, seminars and work observation (55.8 percent). The percentage of those who found the culture, custom and local identity of the market impressive was 49.5. A price range of 1,000-2,000 baht for the travelling expenses per person had the highest percentage of 50.3. Food and beverages were the items most spent on by tourists (60.8 percent). Travelling at weekends was at a percentage of 70.8 , while travelling in the period of January to March was at 47.8 percent. Those getting travelling information from friends had a percentage of 42.8 and those who wanted to go back to the market if possible were at 53.5 percent. According to Mohammad and son (2010), tourists have travelling behavior driven by internal factors such as push motivation, which is the desire to visit new places they have never been to before in order to broaden their experience of life and of traditions, art and culture different from their normal life.

2. Factors that are connected with the travelling behavior of tourists who visited $100-$ Year - Old Samchuk Market were personal factors. There were more female tourists than their male counterparts. The tourists were aged between 50 and 59 years with education level of a bachelor's degree and were civil servants. Differences in age, education, profession and income 
have an impact on the choice of product purchases, accompanying people and tourist destinations to various degrees. Different travelling behavior causes variations in money spent on travelling per capita which is consistent with the research work by Nana Srithammasak, Supaphorn Akkapin et al. (2017). The researchers established that tourists with different demographic backgrounds have different travelling patterns. Female tourists put more emphasis on selecting and buying products than male travellers. Discrepancy in age leads to the purchase of different goods. Different educational backgrounds result in the selection of accompanying friends as well as differences in travelling information and profession. Economic factors such as income per month also play a part in choosing and spending, which in turn, determine product characteristics and tourist destinations. Besides those mentioned above, tourism promotion by the state, variousness of products, local identities, cleanliness of tourist destinations and online publicity of tourism are all most vital to travelling decision making. The fidings are correspondent with the research work by Supattra Huabcharoen, Nantinee Thongorn et al. (2016) which discovered that tourists are contented with products in terms of merchandise diversity and marketing promotion via online media and varied types of advertisement such as Facebook or government websites.

\section{Suggestion}

The research reveals that local identies, tourist destinations and products play an integral role in tourists' decision to visit 100 - Year - Old Samchuk Market, especially regarding products which contribute to travelling expenses per person because the tourists travelling there want to buy products more than other kinds of activity. The market should make product recommendations to tourists and allow them to participate in activities of the shops in order to boost consumption, make a good impression on tourists and help travellers get to know the products better.

\section{Suggestions for subsequent research}

Tourists' travelling behavior from other destinations in Suphanburi should be examined to use the findings to make plans and develop Suphanburi's tourism industry into a secondary province that generates more revenue for Thailand's tourism industry.

\section{References}

Kamonphopthip Pala (20 012 ). Consumer decision-making process in Mueang Chiang Mai district in the purchase of digital single-lens reflex cameras.(Independent study, Master's degree). Chiang Mai University,Faculty of Business Administration in Marketing.

Mingsan Khao Sa-ard et al. (2013). Economics on Tourism. 1st edition. Chiang Mai: Institute of Public Policy Studies. 
Narathip Chutiwong. (2005). Microeconomic Theory. 8th Edition. Bangkok:

Chulalongkorn University Press.

Nana Srithammasak Supaphorn Akkapin et al. (2018). The Study of Foreign Tourists Behavior towards Taling-Chan Floating Market. Journal of Thai Hospitality and Tourism, 13(1), 27-35.

Supattra Huabcharoen Nantinee Thongorn et al. (2017). Behavior and Satisfaction of

Tourists in Thailand : Case Study of Khlong Phadung Krung Kasem Floating Market Dusit Area, Bangkok. Journal of Thai Hospitality and Tourism, 12(2), 82-93.

Tourism Authority of Thailand. (2019). Summary of the annual tourism promotion plan in 2019. Available [On-line] https://www.tourismthailand.org/fileadmin/downloads/pdf/ Summary of the annual tourism promotion plan-2019, [2019, February 17]. 